\title{
Identification of hydrological model parameter variation using ensemble Kalman filter
}

\author{
Chao Deng ${ }^{1,2}$, Pan Liu ${ }^{1,2}$, Shenglian Guo ${ }^{1,2}$, Zejun Li ${ }^{1,2}$, and Dingbao Wang ${ }^{3}$ \\ ${ }^{1}$ State Key Laboratory of Water Resources and Hydropower Engineering Science, Wuhan University, Wuhan, China \\ ${ }^{2}$ Hubei Provincial Collaborative Innovation Center for Water Resources Security, Wuhan, China \\ ${ }^{3}$ Department of Civil, Environmental \& Construction Engineering, University of Central Florida, Orlando, FL, USA
}

Correspondence to: Pan Liu (liupan@whu.edu.cn)

Received: 21 July 2016 - Published in Hydrol. Earth Syst. Sci. Discuss.: 10 August 2016

Revised: 30 October 2016 - Accepted: 27 November 2016 - Published: 16 December 2016

\begin{abstract}
Hydrological model parameters play an important role in the ability of model prediction. In a stationary context, parameters of hydrological models are treated as constants; however, model parameters may vary with time under climate change and anthropogenic activities. The technique of ensemble Kalman filter (EnKF) is proposed to identify the temporal variation of parameters for a two-parameter monthly water balance model (TWBM) by assimilating the runoff observations. Through a synthetic experiment, the proposed method is evaluated with time-invariant (i.e., constant) parameters and different types of parameter variations, including trend, abrupt change and periodicity. Various levels of observation uncertainty are designed to examine the performance of the EnKF. The results show that the EnKF can successfully capture the temporal variations of the model parameters. The application to the Wudinghe basin shows that the water storage capacity (SC) of the TWBM model has an apparent increasing trend during the period from 1958 to 2000. The identified temporal variation of SC is explained by land use and land cover changes due to soil and water conservation measures. In contrast, the application to the Tongtianhe basin shows that the estimated SC has no significant variation during the simulation period of 1982-2013, corresponding to the relatively stationary catchment properties. The evapotranspiration parameter $(C)$ has temporal variations while no obvious change patterns exist. The proposed method provides an effective tool for quantifying the temporal variations of the model parameters, thereby improving the accuracy and reliability of model simulations and forecasts.
\end{abstract}

\section{Introduction}

Hydrological model parameters are critically important for accurate simulation of runoff. Parameters of conceptual hydrological models can be considered as a simplified representation of the physical characteristics in hydrologic processes. Therefore, parameter values are closely related to the catchment conditions, such as climate change, afforestation and urbanization (Peel and Blöschl, 2011). In hydrological modeling, parameters are usually assumed to be stationary; i.e., the calibrated parameters are constants during the calibration period, and have extrapolative ability outside the range of the observations used for parameter estimation (Merz et al., 2011). The estimated parameters usually depend on the calibration period since the calibration period may contain different climatic conditions and hydrological regimes compared to the simulation period (Merz et al., 2011; Zhang et al., 2011; Coron et al., 2012; Seiller et al., 2012; Westra et al., 2014; Patil and Stieglitz, 2015). The model parameters may change as a response to the variations in climatic conditions and catchment properties. For example, land use and land cover changes contribute to temporal changes of model parameters (Andréassian et al., 2003; Brown et al., 2005; Merz et al., 2011). Therefore, it is no longer appropriate to treat parameters as time invariant.

Time-variant hydrological model parameters have been reported in a few recent publications (Merz et al., 2011; Brigode et al., 2013; Jeremiah et al., 2013; Thirel et al., 2015; Westra et al., 2014; Patil and Stieglitz, 2015). For example, Ye et al. (1997) and Paik et al. (2005) mentioned the seasonal variations of hydrological model parameters. Merz et al. (2011) analyzed the temporal changes of model parame- 
ters, which were calibrated by using six consecutive 5-year periods between 1976 and 2006 for 273 catchments in Austria. Recently, Westra et al. (2014) proposed a strategy to cope with nonstationarity of hydrological model parameters, which were represented as a function of a time-varying covariate set before using an optimization algorithm for calibration. Previous studies provided two main methods to estimate the time-variant model parameters: (1) available historical records are divided into consecutive subsets, and parameters are calibrated separately for each subset using an optimization algorithm (Merz et al., 2011; Thirel et al., 2015); (2) a functional form of selected time-variant model parameters is constructed, and the parameters for the function are estimated using an optimization algorithm based on the entire historical record (Jeremiah et al., 2013; Westra et al., 2014).

The data assimilation (DA) actually provides another method to identify the potential temporal variations of model parameters by updating them in real time when observations are available (Liu and Gupta, 2007; Xie and Zhang, 2013). The DA method has been widely applied in hydrology for soil moisture estimation (Han et al., 2012; Kumar et al., 2012; Yan et al., 2015) and flood forecasting (Y. Li et al., 2013; Liu et al., 2012; Abaza et al., 2014). It has also been successfully used to estimate model parameters (Moradkhani et al., 2005; Kurtz et al., 2012; Montzka et al., 2013; Panzeri et al., 2013; Vrugt et al., 2013; Xie and Zhang, 2013; Shi et al., 2014; Xie et al., 2014). For example, Vrugt et al. (2013) proposed two Particle-DREAM (DiffeRential Evolution Adaptive Metropolis) methods, i.e., ParticleDREAM for time-variant and time-invariant parameters, to track the evolving target distribution of HyMOD parameters, while both results were approximately similar and statistically coherent since only 3 years of data were used. Xie and Zhang (2013) used a partitioned forecast-update scheme based on the ensemble Kalman filter (EnKF) to retrieve optimal parameters in a distributed hydrological model. Although the DA method has been used to estimate model parameters, these studies are focused on the estimation of constant parameters. Little attention has been paid to the identification of time-variant model parameters by using the DA method.

The aim of this study is to assess the capability of the EnKF to identify the temporal variations of the model parameters for a monthly water balance model. Thus, a synthetic experiment, including four scenarios with different parameter variations and one scenario with time-invariant parameters, is designed for parameter estimation at different uncertainty levels. Furthermore, two case studies are implemented to estimate the model parameter series and to interpret the parameter variations in response to the changes in catchment characteristics, i.e., land use and land cover. The remainder of this paper is organized as follows. Section 2 presents a brief review of the monthly water balance model and the EnKF method. Following the methodology, Sect. 3 describes the synthetic experiment and the application to two case studies. Results and discussion are presented in Sect. 4 , followed by conclusions in Sect. 5 .

\section{Methodology}

\subsection{Monthly water balance model}

The two-parameter monthly water balance model (TWBM), developed by Xiong and Guo (1999), has been widely applied for monthly runoff simulation and forecast (Guo et al., 2002, 2005; Xiong and Guo, 2012; S. Li et al., 2013; Zhang et al., 2013; Xiong et al., 2014). The inputs of the model include monthly areal precipitation and potential evapotranspiration. The actual monthly evapotranspiration is calculated as follows:

$E_{i}=C \times \mathrm{EP}_{i} \times \tanh \left(\frac{P_{i}}{\mathrm{EP}_{i}}\right)$,

where $E_{i}$ represents the actual monthly evapotranspiration; $\mathrm{EP}_{i}$ and $P_{i}$ are the monthly potential evapotranspiration and precipitation, respectively; $C$ is the first model parameter; and $i$ is the time step.

The monthly runoff is dependent on the soil water content and is calculated by the following equation:

$Q_{i}=S_{i} \times \tanh \left(\frac{S_{i}}{\mathrm{SC}}\right)$,

where $Q_{i}$ is the monthly runoff and $S_{i}$ is the soil water content. As the second model parameter, SC represents the water storage capacity of the catchment in millimeters. The available water for runoff at the $i$ th month is computed by $S_{i-1}+P_{i}-E_{i}$. Then, the monthly runoff is calculated as

$Q_{i}=\left(S_{i-1}+P_{i}-E_{i}\right) \times \tanh \left(\frac{S_{i-1}+P_{i}-E_{i}}{\mathrm{SC}}\right)$.

Finally, the soil water content at the end of each time step is updated based on the water conservation law:

$S_{i}=S_{i-1}+P_{i}-E_{i}-Q_{i}$.

\subsection{Ensemble Kalman filter}

As a sequential data assimilation technique, EnKF is essentially the Monte Carlo implementation of the Kalman filter, producing an ensemble of state simulations for updating the state variables and their covariance matrices (Evensen, 1994; Burgers et al., 1998; Moradkhani et al., 2005; Shi et al., 2014). It is applicable to a variety of nonlinear problems (Evensen, 2003; Weerts and El Serafy, 2006) and has been widely applied to hydrological models (Abaza et al., 2014; DeChant and Moradkhani, 2014; Delijani et al., 2014; Samuel et al., 2014; Tamura et al., 2014; Xue and Zhang, 
Table 1. States and parameters of the two-parameter monthly water balance model.

\begin{tabular}{llll}
\hline \multicolumn{2}{l}{ Parameters and state variables } & Description & Ranges and unit \\
\hline Parameter & $C$ & Evapotranspiration parameter & $0.2-2.0(-)$ \\
& SC & Catchment water storage capacity & $100-4000(\mathrm{~mm})$ \\
State variable & $S$ & Soil water content & $\mathrm{mm}$ \\
\hline
\end{tabular}

2014; Deng et al., 2015). Furthermore, the EnKF has been successfully used in time-invariant parameter estimations for hydrological models (Moradkhani et al., 2005; Wang et al., 2009; Xie and Zhang, 2010, 2013).

In this paper, the EnKF is applied to simultaneously estimate state variables and parameters (Table 1) in the TWBM model. The augmented state vector includes both states and model parameters (Wang et al., 2009), i.e., $Z=(\theta, x)^{T}$, where $\theta$ includes the evapotranspiration parameter $(C)$ and the catchment water storage capacity (SC), and $x$ is the soil water content $(S)$. The model forecast is conducted for each ensemble member as follows:

$\left(\begin{array}{c}\theta_{i+1 \mid i}^{k} \\ x_{i+1 \mid i}^{k}\end{array}\right)=\left(\begin{array}{c}\theta_{i \mid i}^{k} \\ f\left(x_{i \mid i}^{k}, \theta_{i+1 \mid i}^{k}, u_{i+1}\right)\end{array}\right)+\left(\begin{array}{c}\delta_{i}^{k} \\ \varepsilon_{i}^{k}\end{array}\right)$,

where $\delta_{i}^{k} \sim N\left(0, U_{i}\right), \varepsilon_{i}^{k} \sim N\left(0, G_{i}\right)$,

$\theta_{i+1 \mid i}^{k}$ is the $k$ th ensemble member forecast of model parameters at time $i+1 ; \theta_{i \mid i}^{k}$ is the $k$ th updated ensemble member of model parameters at time $i ; x_{i+1 \mid i}^{k}$ is the $k$ th ensemble member forecast of model state at time $i+1 ; x_{i \mid i}^{k}$ is the $k$ th updated ensemble member of model state at time $i ; f$ is the forecasting model operator, i.e., the TWBM model; $u_{i+1}$ is the forcing data for the hydrological model, including precipitation and potential evapotranspiration; $\varepsilon_{i}^{k}$ and $\delta_{i}^{k}$ are the independent white noise for the forecasting model, following a Gaussian distribution with zero mean and specified covariance $G_{i}$ and $U_{i}$, respectively. Note that the parameters in Eq. (5) are propagated by adding random disturbances to the parameter member between time steps (Wang et al., 2009).

The observation ensemble member can be written as

$y_{i+1}^{k}=h\left(x_{i+1 \mid i}^{k}, \theta_{i+1 \mid i}^{k}\right)+\xi_{i+1}^{k}, \xi_{i+1}^{k} \sim N\left(0, W_{i+1}\right)$,

where $y_{i+1}^{k}$ is the $k$ th ensemble member of the model simulated runoff at time $i+1 ; h$ is the observation operator which represents the relationship between the observation and the state variables; $\xi_{i+1}^{k}$ is the noise term, which follows a Gaussian distribution with zero mean and specified covariance $W_{i+1}$.

Based on the available state and observation equations, the model parameters and state are updated according to the following equation:

$$
Z_{i+1 \mid i+1}^{k}=Z_{i+1 \mid i}^{k}+K_{i+1}\left(y_{i+1}^{k}-h\left(Z_{i \mid i}^{k}\right)\right),
$$

where $Z$ is the augmented state vector that includes both states and parameters; $y_{i+1}^{k}$ is the $k$ th observation ensemble member generated by adding the observation error $\xi_{i+1}^{k}$ to the observed runoff:

$y_{i+1}^{k}=y_{i+1}+\xi_{i+1}^{k}$,

$K_{i+1}$ is the Kalman gain matrix that represents the weight between the forecasts and observations. It can be calculated as (Evensen, 1994, 2003; Evensen and van Leeuwen, 1996; Moradkhani et al., 2005)

$K_{i+1}=\sum_{i+1 \mid i}^{z y}\left(\sum_{i+1 \mid i}^{y y}+W_{i+1}\right)^{-1}$,

where $\sum_{i+1 \mid i}^{z y}$ is the cross-covariance of the forecasted state and parameters and $\sum_{i+1 \mid i}^{y y}$ is the error covariance of the forecasted output. The error covariance matrix is calculated based on the forecasted ensemble members:

$\sum_{i+1 \mid i}=\frac{1}{N-1} Z_{i+1 \mid i} Z_{i+1 \mid i}^{T}$

where $Z_{i+1 \mid i}=\left(z_{i+1 \mid i}^{1}-\bar{z}_{i+1 \mid i}, \cdots, z_{i+1 \mid i}^{N}-\bar{z}_{i+1 \mid i}\right) ; \bar{z}_{i+1 \mid i}$ is the ensemble mean of the forecasted members, and $N$ is the ensemble size.

Since the parameters are limited within a range, the constrained EnKF (Wang et al., 2009) is used in this study. The ensemble size, uncertainties in input and output have significant impacts on the assimilation performance of the EnKF, and they are specified following the previous studies (Moradkhani et al., 2005; Wang et al., 2009; Xie and Zhang, 2010; Nie et al., 2011; Lü et al., 2013; Samuel et al., 2014). The ensemble size is set to 1000 for the synthetic experiment and the two case studies. In the present study, the uncertainties, including state variable and parameter errors ( $\varepsilon$ and $\delta$ in Eq. 5, respectively) and runoff observation error ( $\xi$ in Eq. 6), are assumed to follow a Gaussian distribution with zero mean and specified covariance. Note that the model parameter errors should vary depending on the hydrological model used and the study basin (Clark et al., 2008). Larger standard deviation can generate greater perturbations to model parameters, and it can improve the coverage of updated parameters but also may cause fluctuations in the estimates. In this study, the parameter errors are determined empirically; i.e., the standard deviation of $C$ is set to 0.01 for all the cases, while 
that of SC is set to 5.0, 1.0 and 0.5 in the synthetic experiment, Wudinghe basin and Tongtianhe basin, respectively. The standard deviations of both model state and observation errors are assumed to be proportional to the magnitude of true values (Wang et al., 2009; Lü et al., 2013). The proportional factors of the model state are set to 0.05 for all the cases. Different proportional factors of runoff observation and precipitation (Table 3) are evaluated to examine the capability of the EnKF in the synthetic experiment, whereas the proportional factors of runoff observation are set to 0.1 and zero precipitation errors are assumed in the two case studies.

\subsection{Evaluation index}

Two evaluation criteria, including the Nash-Sutcliffe efficiency (NSE) (Nash and Sutcliffe, 1970) and the volume error (VE) are used to evaluate the runoff assimilation results for the synthetic experiment and the application to real catchments (Deng et al., 2015; Li et al., 2015).

$$
\begin{aligned}
& \mathrm{NSE}=1-\frac{\sum_{i=1}^{n}\left(Q_{\mathrm{sim}, i}-Q_{\mathrm{obs}, i}\right)^{2}}{\sum_{i=1}^{n}\left(Q_{\mathrm{obs}, i}-\bar{Q}_{\mathrm{obs}}\right)^{2}}, \\
& \mathrm{VE}=\frac{\sum_{i=1}^{n} Q_{\mathrm{sim}, i}-\sum_{i=1}^{n} Q_{\mathrm{obs}, i}}{\sum_{i=1}^{n} Q_{\mathrm{obs}, i}},
\end{aligned}
$$

where $Q_{\mathrm{sim}, i}$ and $Q_{\mathrm{obs}, i}$ are the simulated and observed runoff for the $i$ th month, $\bar{Q}_{\text {obs }}$ is the mean value of the observed runoff and $n$ is the total number of data points. The NSE ranges from $-\infty$ to 1 and has been widely used to assess the goodness of fit for hydrological modeling. A NSE value of 1 stands for a perfect match of simulated runoff to the observations, whereas a value of 0 indicates that the model simulations are equivalent to the mean value of the runoff observations; negative NSE values indicate that the mean observed runoff is better than the model simulations. The VE is a measure of bias between the simulated and observed runoff. For example, VE with the value of 0 denotes no bias, and a negative value means an underestimation of the total runoff volume.

The assimilated parameter results are evaluated using the following criteria, including the Pearson correlation coefficient $(R)$, the root mean square error (RMSE) and mean absolute relative error (MARE):

$$
\begin{aligned}
& R=\frac{\sum_{i=1}^{n}\left(\theta_{\mathrm{sim}, i}-\bar{\theta}_{\mathrm{sim}}\right)\left(\theta_{\mathrm{obs}, i}-\bar{\theta}_{\mathrm{obs}}\right)}{\sqrt{\sum_{i=1}^{n}\left(\theta_{\mathrm{sim}, i}-\bar{\theta}_{\mathrm{sim}}\right)^{2}\left(\theta_{\mathrm{obs}, i}-\bar{\theta}_{\mathrm{obs}}\right)^{2}}}, \\
& \mathrm{RMSE}=\sqrt{\frac{1}{n} \sum_{i=1}^{n}\left(\theta_{\mathrm{sim}, i}-\theta_{\mathrm{obs}, i}\right)^{2}} \\
& \text { MARE }=\frac{1}{n} \sum_{i=1}^{n} \frac{\left|\theta_{\mathrm{sim}, i}-\theta_{\mathrm{obs}, i}\right|}{\theta_{\mathrm{obs}, i}},
\end{aligned}
$$

where $\theta_{\mathrm{sim}, i}$ and $\theta_{\mathrm{obs}, i}$ are the assimilated and true model parameters for the $i$ th month, $\bar{\theta}_{\text {sim }}$ and $\bar{\theta}_{\text {obs }}$ are the mean of the assimilated and true model parameters for the $i$ th month and $n$ is the total number of data points.

\section{Data and study area}

\subsection{Synthetic experiment}

A synthetic experiment is designed to evaluate the capability of the assimilation procedure to identify the temporal variation of model parameters. Five scenarios of different parameter variations are developed, as shown in Table 2. The model parameters in the first four scenarios are time variant, and those in the last scenario are constant. Parameter $C$, the evapotranspiration parameter, is considered to be sinusoidal reflecting potential seasonal variations in hydrological model parameters (Paik et al., 2005; Ye et al., 1997). An increasing trend is also considered to account for the potential annual or long-term variability. The change of parameter SC is considered to be gradual and abrupt, since the catchment water storage capacity can be affected by land use and land cover changes, such as afforestation and dam construction. The parameters in scenario 5 are treated as constants like in conventional hydrological modeling. Observations for precipitation and potential evapotranspiration are generated by adding a Gaussian disturbance to the corresponding data from a real catchment, and runoff is then produced using the TWBM model. The data set used in this experiment is 672 months long. The first 24-month period is set for model warm-up to reduce the impact of the initial soil moisture conditions. The steps toward identifying temporal variation of model parameters are as follows:

1. Time series of model parameters are synthetically generated, including the time-variant parameters and the constant parameters. Model parameter sets are produced using a sinusoidal function and/or a linear trend function within the specified ranges shown in Table 1 . The runoff observations for each scenario are computed from the TWBM model taking monthly potential evapotranspiration, monthly precipitation and the parameters as inputs.

2. The initial ensembles of model parameters and state variables are generated using uniform distributions within the specified ranges in Table 1. The ensemble size and the total number of assimilation time steps are specified.

3. After the initialization of parameters and state variables, the hydrological model parameters and states are updated by assimilating the runoff observations obtained in step (1). The additive errors for generating the ensemble members of model parameters, state variables and runoff observations are obtained from Gaussian distributions with zero mean and specified variance.

To evaluate the effects of errors on identifying parameter variation, different levels of observation uncertainty are considered in the synthetic experiment, as detailed in Table 3. The uncertainties from the observed precipitation and runoff are characterized by adding Gaussian noises, where standard 
Table 2. Different variations of model parameters in the synthetic experiment.

\begin{tabular}{ll}
\hline Scenario & Description \\
\hline Scenario 1 & $C$ has a periodic variation, and SC has an increasing trend \\
Scenario 2 & $C$ has a periodic variation, and SC has an abrupt change \\
Scenario 3 & $C$ has a periodic variation with an increasing trend, and SC has an increasing trend \\
Scenario 4 & $C$ has a periodic variation with an increasing trend, and SC has an abrupt change \\
Scenario 5 & Both $C$ and SC are constant
\end{tabular}

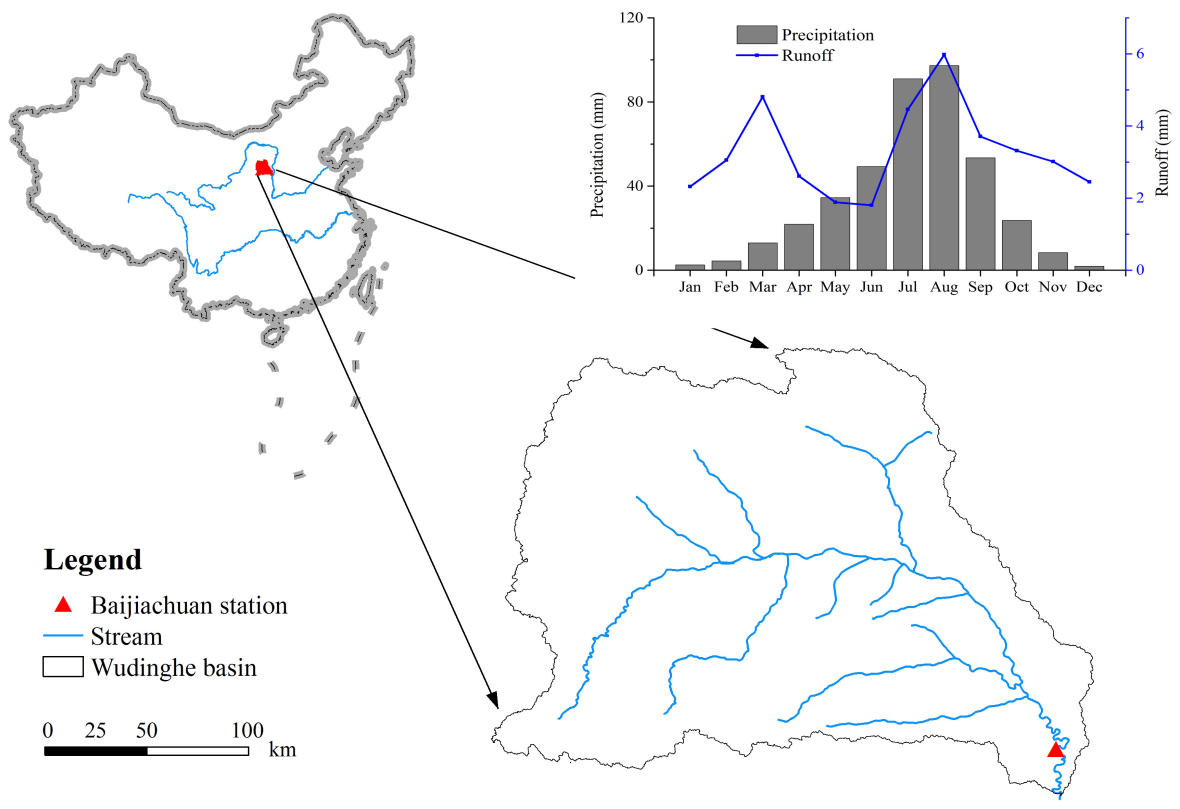

Figure 1. Location and mean monthly precipitation and runoff from 1956 to 2000 of the Wudinghe basin.

Table 3. Proportional factors of the standard deviations for precipitation $\left(\gamma_{P}\right)$ and runoff $\left(\gamma_{Q}\right)$ uncertainties.

\begin{tabular}{lrrr}
\hline Type & Low level & Medium level & High level \\
\hline$\gamma_{P}$ & 0 & 0.05 & 0.10 \\
$\gamma_{Q}$ & 0.05 & 0.10 & 0.20 \\
\hline
\end{tabular}

deviations are assumed to be proportional to the magnitude of the true values, and the corresponding proportional factors are denoted as $\gamma_{P}$ and $\gamma_{Q}$. The proportional factors are set to account for the practical measurement error (Wang et al., 2009; Xie and Zhang, 2010).

\subsection{Study area}

\subsubsection{Case 1: Wudinghe basin}

The method is applied to the Wudinghe basin (Fig. 1), which is a sub-basin of the Yellow River basin and located in the southern fringe of the Maowusu Desert and the northern part of the Loess Plateau in China, where the climate is semiarid climate. It has a drainage area of approximately $30261 \mathrm{~km}^{2}$ and a total length of $491 \mathrm{~km}$. The Wudinghe basin has an average slope of $0.2 \%$, and its elevation ranges from 600 to $1800 \mathrm{~m}$ above the sea level. The Baijiachuan gauge station, which is the most downstream station of the Wudinghe basin, drains $98 \%$ of the total basin area. The mean annual precipitation over the basin is $401 \mathrm{~mm}$, of which $72.5 \%$ occurs in the rainy season from June to September (Fig. 2). The mean annual potential evapotranspiration is $1077 \mathrm{~mm}$, and the mean annual runoff is about $39 \mathrm{~mm}$ with a runoff coefficient of 0.1 .

The soil erosion is severe in the Wudinghe basin, owing to the highly erodible loess and sparse vegetation. Since the $1960 \mathrm{~s}$, the soil and water conservation measures have been undertaken. Several engineering measures, including tree and grass plantation, check dam and reservoir construction, and land terracing, were effectively implemented during several decades. The land use changes caused by the soil and water conservation measures had a significant effect on increasing water storage capacity $(\mathrm{Xu}, 2011)$. 


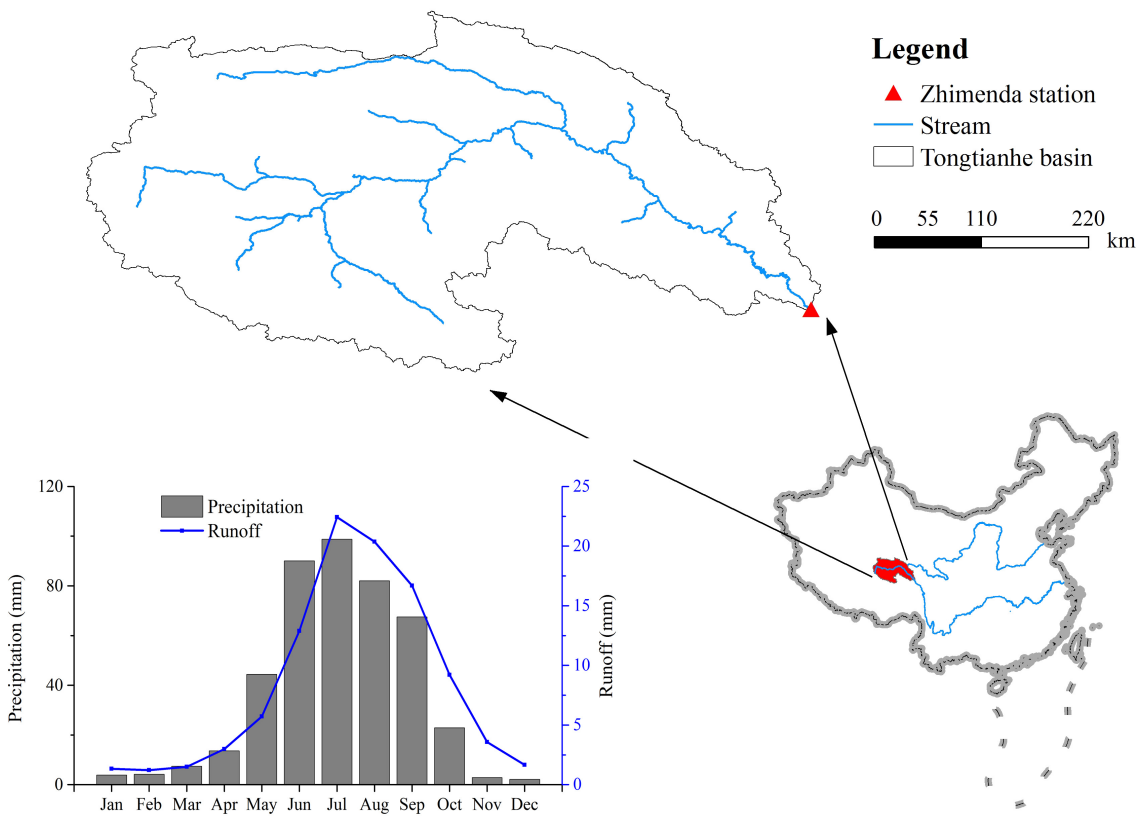

Figure 2. Location and mean monthly precipitation and runoff from 1980 to 2013 of the Tongtianhe basin.
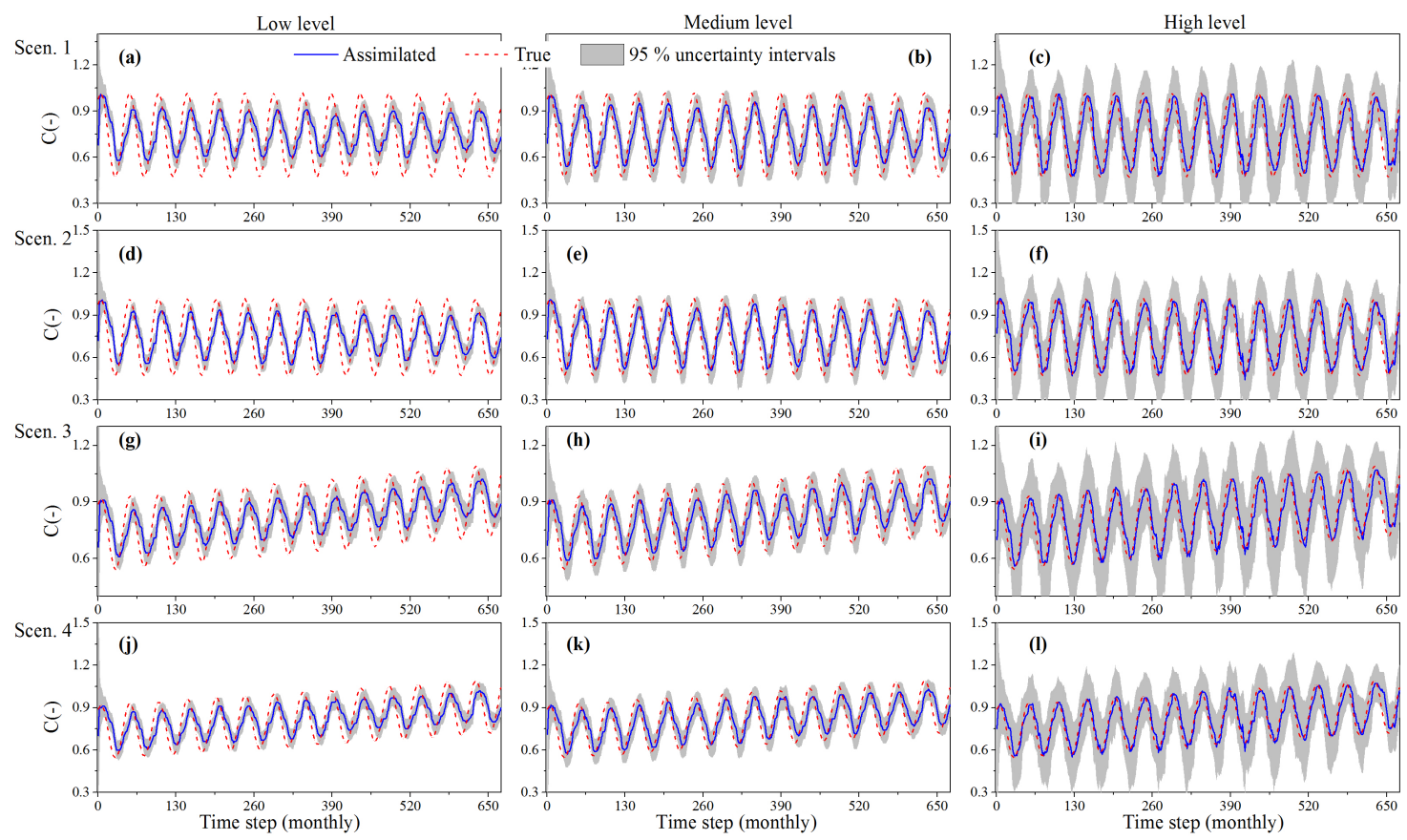

Figure 3. Comparison between estimated $C$ and its true values for various parameter changes under different uncertainty levels. The gray areas represent the $95 \%$ prediction uncertainty intervals.

\subsubsection{Case 2: Tongtianhe basin}

The Tongtianhe basin (Fig. 3) is located in the southwestern Qinghai Province, China, with a continental climate. It belongs to the source area of the Yangtze River basin with a drainage area of about $140000 \mathrm{~km}^{2}$ and a total main stream length of $1206 \mathrm{~km}$. The elevation of the Tongtianhe basin approximately ranges from 3500 to $6500 \mathrm{~m}$ a.s.l. Zhimenda is the basin outlet. The mean annual precipitation over the basin is $440 \mathrm{~mm}$, of which $76.9 \%$ occurs in the period from June to September (Fig. 4). The mean annual potential evapotranspiration is $796 \mathrm{~mm}$, and the mean annual runoff is about 

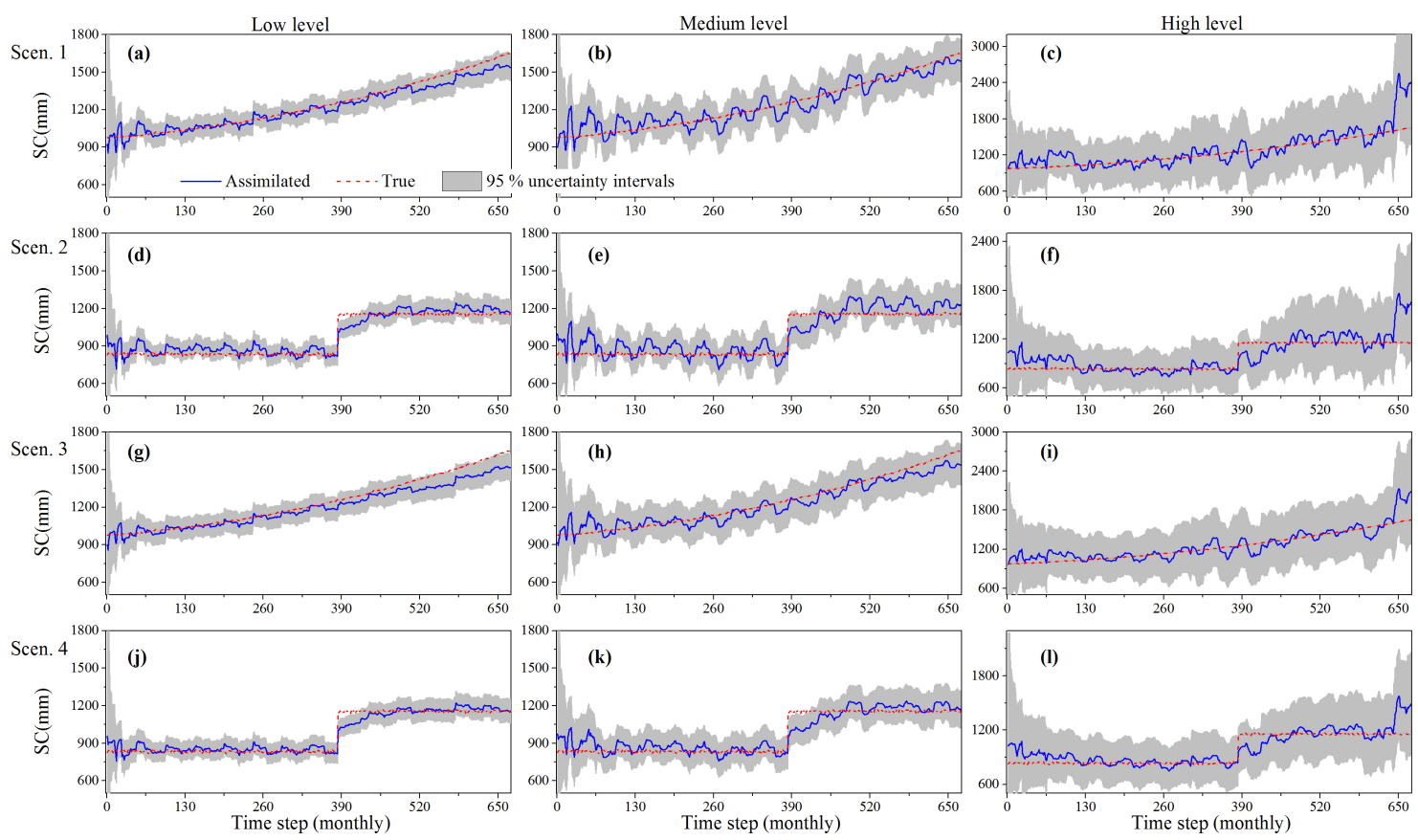

Figure 4. Comparison between estimated SC and its true values for various parameter changes under different uncertainty levels. The gray areas represent the $95 \%$ prediction uncertainty intervals.

$99 \mathrm{~mm}$ with a runoff coefficient of 0.23 . The Tongtianhe basin is rarely affected by human activities, owing to the water source protection guidelines conducted by the government. The Tongtianhe basin is used for comparison on model parameter identification.

\subsubsection{Data}

The data sets used in this study include monthly precipitation, potential evapotranspiration and runoff in the Wudinghe basin (from 1956 to 2000) and the Tongtianhe basin (from 1980 to 2013). The potential evapotranspiration is estimated using the Penman-Monteith equation (Allen et al., 1998) based on the meteorological data from the China Meteorological Data Sharing Service System (http://data.cma.cn). To reduce the impact of the initial conditions, a 2-year data set, i.e., from 1956 to 1957 for Wudinghe basin and from 1980 to 1981 for Tongtianhe basin, is reserved as the warmup period.

\section{Results and discussion}

\subsection{Synthetic experiment}

The comparisons of the estimated and true model parameters under different scenarios are presented in Figs. 3, 4 and 5. Tables 4 and 5 show the evaluated statistics for the parameters and runoff estimations. The assimilated parameter values are obtained from the ensemble mean at each time step. The estimation of parameters $C$ and SC have the similar trends to the true parameter series. The temporal variations of the estimated $C$ agree well with the true series, although it has biases on the peaks of the periodic changes. For SC, the temporal estimates can capture the different changes in Table 2, especially for the abrupt change where the estimated values respond immediately. Different uncertainty levels are considered to examine the capability of the EnKF method. The results in Fig. 3 show that the estimated $C$ has more accurate peaks with smaller RMSE and higher $R$ values under the high-level uncertainty (Table 4); whereas, the SC estimates in Fig. 4 have some fluctuations when the uncertainty level increases. This is due to the estimated values vary with increasing uncertainty levels in the assimilation process. In the synthetic experiment, the true $C$ is assumed to be periodic with a higher degree of variation, whereas the true SC series have less variation.

It should be noted that there are time lags between the assimilated and true $C$. The observation at the current time step is used to adjust the state variables and parameters in EnKF, and the updates of parameters depend on the Kalman gain for parameters. A runoff observation at the current time is determined by states at the current and previous time steps (Pauwels and Lannoy, 2006). The Kalman gain is dependent on the relative value of observation error to model error. The updated states are closer to the observation with a higher Kalman gain (Tamura et al., 2014). The synthetic $C$ series were assumed to be periodic when many peak values exist, whereas the variation of SC series is less. The time lag be- 

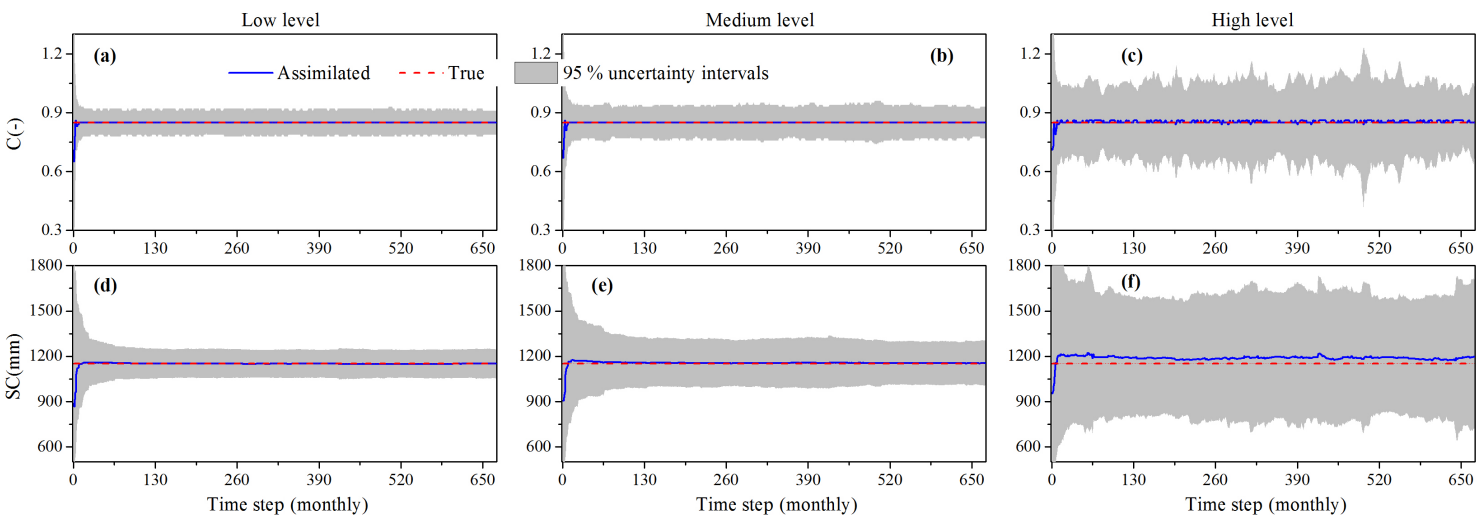

Figure 5. Estimations of time-invariant $C$ and SC under different uncertainty levels. The gray areas represent the $95 \%$ prediction uncertainty intervals.

Table 4. Performance statistics for various changes of (a) parameter $C$ and (b) SC estimations under different levels of uncertainty in the synthetic experiment.

\begin{tabular}{|c|c|c|c|c|c|c|c|c|c|}
\hline \multirow[t]{2}{*}{ Scenario } & \multicolumn{3}{|c|}{ Low level } & \multicolumn{3}{|c|}{ Medium level } & \multicolumn{3}{|c|}{ High level } \\
\hline & RMSE & MARE & $R$ & RMSE & MARE & $R$ & RMSE & MARE & $R$ \\
\hline \multicolumn{10}{|c|}{ (a) Parameter $C$} \\
\hline Scenario 1 & 0.15 & 0.21 & 0.55 & 0.16 & 0.18 & 0.68 & 0.18 & 0.11 & 0.89 \\
\hline Scenario 2 & 0.16 & 0.19 & 0.63 & 0.17 & 0.16 & 0.75 & 0.18 & 0.09 & 0.91 \\
\hline Scenario 3 & 0.12 & 0.13 & 0.64 & 0.13 & 0.11 & 0.72 & 0.14 & 0.07 & 0.91 \\
\hline Scenario 4 & 0.13 & 0.12 & 0.70 & 0.13 & 0.10 & 0.77 & 0.14 & 0.06 & 0.93 \\
\hline Scenario 5 & 0 & - & - & 0 & - & - & 0 & - & - \\
\hline \multicolumn{10}{|c|}{ (b) Parameter SC } \\
\hline Scenario 1 & 182.87 & 0.03 & 0.99 & 187.76 & 0.05 & 0.94 & 253.35 & 0.83 & 0.83 \\
\hline Scenario 2 & 158.30 & 0.04 & 0.96 & 167.47 & 0.07 & 0.91 & 189.59 & 0.80 & 0.80 \\
\hline Scenario 3 & 180.20 & 0.03 & 0.99 & 183.06 & 0.04 & 0.97 & 215.04 & 0.88 & 0.88 \\
\hline Scenario 4 & 156.42 & 0.03 & 0.97 & 158.50 & 0.05 & 0.93 & 170.90 & 0.86 & 0.86 \\
\hline Scenario 5 & 1.54 & - & - & 3.67 & - & - & 20.54 & - & - \\
\hline
\end{tabular}

tween assimilated and true values exists particularly when peak values occur (Clark et al., 2008; Samuel et al., 2014).

The results for the scenario of constant parameters are shown in Fig. 5, demonstrating that the estimated parameters can approach their true values after the initial 24 assimilation steps. The gray areas represent the $95 \%$ prediction uncertainty intervals, which reduce quickly and approach a stable spread. The performance of the estimated parameters is correlated with the uncertainty level. Higher precipitation and runoff observation errors correspond to the greater RMSE values (Table 4) of estimated parameters and uncertainty ranges. The performance of runoff estimations for various parameter changes under different levels of uncertainty is shown in Table 5, suggesting that the EnKF perfectly matches the observations with NSEs higher than 0.95 and absolute VEs smaller than 0.02. The EnKF can successfully capture the temporal variations of the true parameters, although the uncertainty levels of the observations can affect its performance to a certain degree. The above results demonstrate that the EnKF is able to identify the temporal variation of the model parameters by updating the state variables and parameters based on the runoff observations.

\subsection{Case studies}

Figure 6 shows the double mass curve between monthly runoff and precipitation for the Wudinghe and Tongtianhe basins, respectively. Figure 6 a shows the linear relationship between cumulative runoff and precipitation pre- and post1972 in the Wudinghe basin, which is similar to the result presented by $\mathrm{Xu}$ (2011) and Li et al. (2014). The results show two straight lines with different slopes for the relationships between precipitation and runoff, indicating that an abrupt change occurred in 1972; i.e., the runoff generation had been changed from this year due to the soil and water conservation measures. On the other hand, Fig. $6 \mathrm{~b}$ demonstrates that 
Table 5. Performance of runoff estimations for various parameter changes under different levels of uncertainty in the synthetic experiment.

\begin{tabular}{lrrrrrrrr}
\hline Scenario & \multicolumn{2}{c}{ Low level } & & \multicolumn{2}{c}{ Medium level } & & \multicolumn{2}{c}{ High level } \\
\cline { 2 - 3 } \cline { 8 - 9 } & NSE & VE & & NSE & VE & & NSE & VE \\
\hline Scenario 1 & 0.999 & -0.0003 & & 0.988 & -0.0046 & & 0.967 & -0.0230 \\
Scenario 2 & 0.999 & 0.0001 & & 0.990 & -0.0028 & & 0.967 & -0.0141 \\
Scenario 3 & 0.999 & -0.0011 & & 0.990 & -0.0013 & & 0.974 & -0.0264 \\
Scenario 4 & 0.999 & -0.0009 & & 0.992 & 0.0002 & & 0.959 & -0.0147 \\
Scenario 5 & 0.999 & -0.0022 & & 0.992 & -0.0077 & & 0.961 & -0.0187 \\
\hline
\end{tabular}
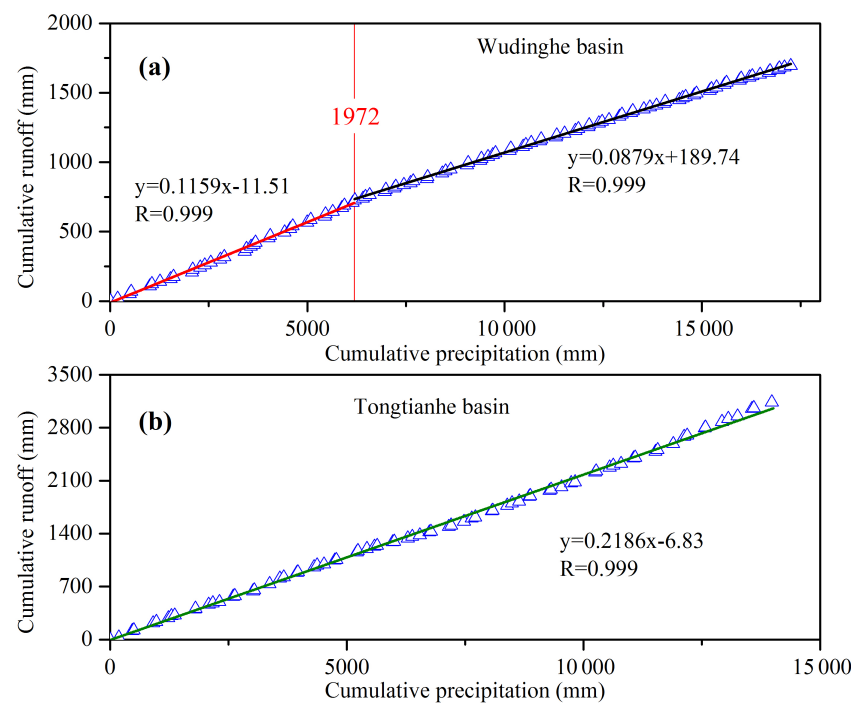

Figure 6. Double mass curve between monthly runoff and precipitation for Wudinghe basin within the period of 1958-2000 (a) and Tongtianhe basin within the period of 1982-2013 (b).

a single linear relationship fits all the data for the Tongtianhe basin, suggesting a stable precipitation-runoff relationship during the 1982-2013 period.

The estimated parameters and the associated $95 \%$ prediction uncertainty intervals are shown in Fig. 7. The time series of estimated SC shows an apparent increasing trend, with two different trends for pre- and post-turning points in Fig. 6a. The temporal variation of the water storage capacity is correlated with the changes of land use and land cover. Both the trends in Fig. 7c show an increase of SC because the implementation of the large-scale engineering measures significantly improved the water holding capacity of the Wudinghe basin, especially for the reservoir and check dam construction. The trend slopes of the two periods, one from 1956 to 1971 and the other from 1972 to 2000, are different because the degree of implementing engineering measures varied during the period of 1958-2000. Moreover, the increase of the water holding capacity slowed down during the 1980s due to the sedimentation in reservoirs and check dams after periods of operation (Wang and Fan, 2003). Figure 8a shows the long-term time series of precipitation and potential evaporation in the Wudinghe basin. The result shows that the runoff decreases significantly while precipitation changes slightly and potential evaporation has no trend, indicating that the actual evaporation increases significantly due to impacts of human activities, i.e., soil and water conservation measures. Figure $8 \mathrm{~b}$ presents the runoff reduction caused by all the soil and water conservation measures, i.e., land terracing, tree and grass plantation and check dam and reservoir construction. The runoff reduction positively relates to the water holding capacity, namely the SC value. The slope for the period of 1958-1971 is higher than that for the period of 1972-1996, suggesting that the $\mathrm{SC}$ in the former period has a higher increasing trend. On the other hand, results of Tongtianhe basin show that the estimated SC has no detectable trend with a small $R$ value. Moreover, the ranges and standard deviation of the estimated SC values are much smaller than those in the Wudinghe basin (Fig. 7), suggesting that the estimated $\mathrm{SC}$ has no obvious temporal variations.

For parameter $C$, the results show that the estimates have no significant temporal patterns because the trend line slopes are almost zero and the standard deviations are relatively small for the two basins (Fig. 7a and b); however, it can be treated as a time-variant parameter since temporal variations exist in the estimated $C$ series. The temporal variations of the estimated $C$ are related to the variation of monthly actual evaporation, which is affected by multiple climatic factors, such as air temperature, soil moisture and solar irradiance (Su et al., 2015). The gray regions represent the $95 \%$ prediction uncertainty intervals obtained from the parameter ensembles. The stable and narrow uncertainty bounds shown in Fig. 7 indicate that the EnKF can provide superior performance of parameter estimation. The runoff simulations for both basins match well with the runoff observations. Specifically, the NSE and VE for the Wudinghe basin are 0.93 and 0.07 , respectively. While the corresponding index values for the Tongtianhe basin are 0.99 and 0.04 .

In summary, the above results demonstrate that the EnKF can identify the temporal variation of model parameters well by updating both state variables and parameters based on the runoff observations. The trends of parameter SC can be explained by the changes of catchment characteristics (i.e., land use and land cover) in the Wudinghe basin. However, 

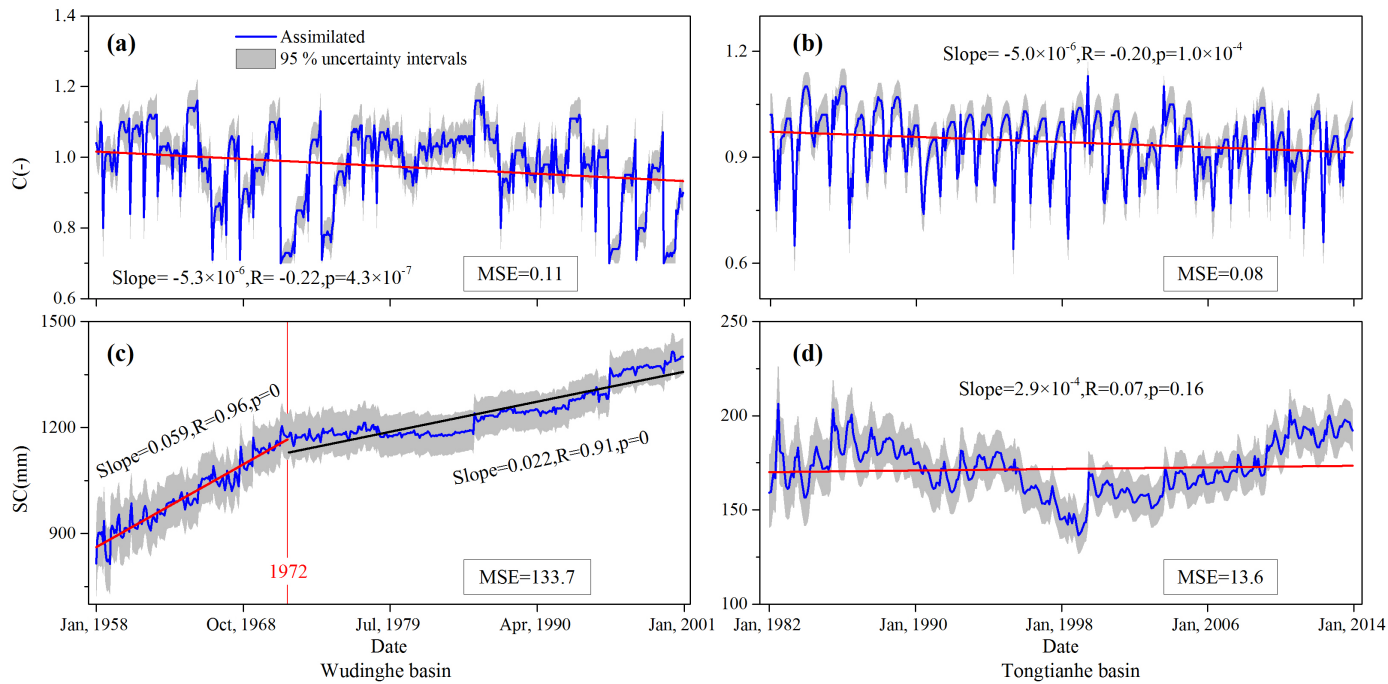

Figure 7. Estimated parameter values of $C$ and SC for (1) Wudinghe basin within the period of 1958-2000, and (2) Tongtianhe basin within the period of 1982-2013. The gray areas represent the $95 \%$ prediction uncertainty intervals. Note that the MSE denotes the standard deviation of the estimated parameter values.
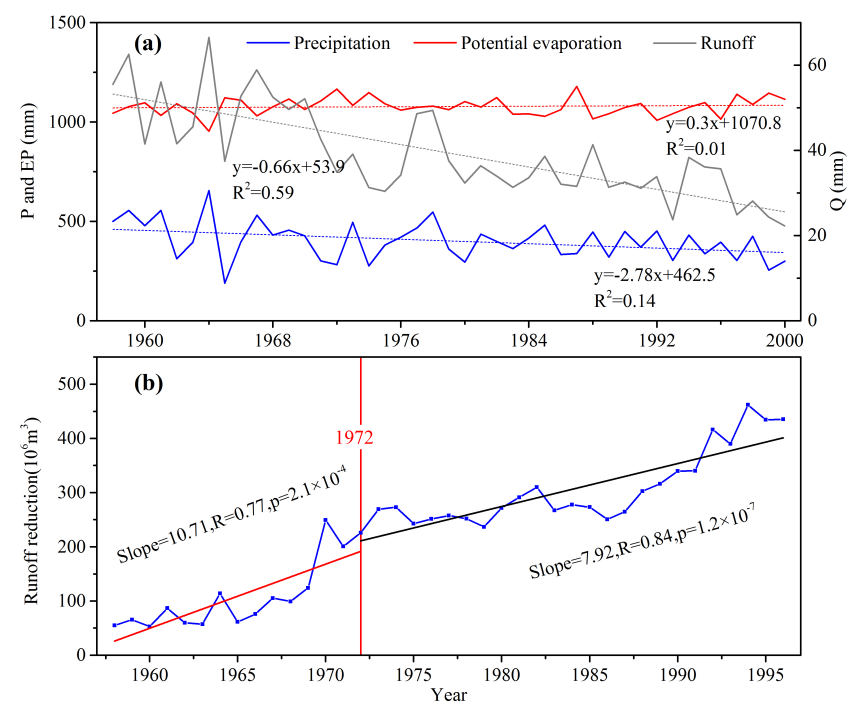

Figure 8. (a) Yearly precipitation, potential evaporation and runoff in Wudinghe basin during the period of 1958-2000; (b) Runoff reduction in Wudinghe basin caused by all the soil and water conservation measures, i.e., land terracing, tree and grass plantation and check dam and reservoir construction for the period of 1958-1996. Note that the data are from Wang and Fan (2003) and are only available from 1956 to 1996.

the estimated SC for the Tongtianhe basin is approximately stable with a small standard deviation because the basin is located in a water protection zone and has no significant changes on water storage capacity caused by human activities. The parameter $C$ has temporal variations and can be treated as a time-variant parameter for both basins, although the estimates have no obvious temporal patterns. Therefore, the EnKF is capable of identifying the temporal variations of model parameters.

\section{Conclusions}

This study proposes an ensemble Kalman filter (EnKF) to identify the temporal variation of model parameters of the two-parameter monthly water balance model (TWBM) by assimilating runoff observations. A synthetic experiment, which contains four scenarios with different changes of model parameters and one scenario with constant parameters, is designed to examine the capability of the proposed approach. Furthermore, three different levels of observation uncertainty are taken to assess the performance of the EnKF. The main conclusions are as follows. For the time-variant parameters, the EnKF provides superior performance even though slight time lags exist for parameters with periodic variations. The true values of the constant parameters can be approached quickly after 24 time steps of the assimilation process. The temporal variations of the parameters can be successfully captured even under a high level of observation uncertainties, which would have an influence on the performance of the EnKF.

The EnKF method is applied to the Wudinghe basin in China, aiming to detect the temporal variations of the model parameters and to provide an explanation for the parameter variation from the perspective of catchment characteristic changes. Meanwhile, a comparison is implemented to investigate the variation of model parameters in the Tongtianhe basin, which is barely affected by human activities. The parameter of water storage capacity (SC) for the monthly water balance model shows a significant increasing trend for the 
period of 1958-2000 in the Wudinghe basin. The soil and water conservation measures, including land terracing, tree and grass plantation and check dam and reservoir construction, were implemented from 1958 to 2000 , resulting in the increase of the water holding capacity of the basin, which explains the increasing trend of SC. Moreover, the magnitudes of the engineering measures in different time periods play an important role in the degree of increasing trend for SC. In the Tongtianhe basin, the parameter SC has no significant trend for the period of 1982-2013, which is consistent with the relatively stationary catchment characteristics. The evapotranspiration parameter $(C)$ has temporal variations and can be treated as a time-variant parameter, but no obvious trends exist.

The method proposed in this paper provides an effective tool for the time-variant model parameter identification. Future work will be focused on the influence of the correlations between/among model parameters and performance comparison of multiple data assimilation methods.

\section{Data availability}

The meteorological data can be requested and obtained from the China Meteorological Data Sharing Service System (http: //data.cma.cn). According to the website's data sharing rules, data sets from the website cannot be uploaded or shared personally. However, readers can access the data themselves through registration. Note that the runoff data from the local hydrology bureau is also not publicly accessible. The hydrological data, including the precipitation and runoff records, are managed by local Hydrology and Water Resources Bureau of China.

Acknowledgements. This study was supported by the Excellent Young Scientist Foundation of NSFC (51422907) and the Open Foundation of State Key Laboratory of Water Resources and Hydropower Engineering Science in Wuhan University (2015SWG01). The authors thank the China Meteorological Data Sharing Service System for providing part of the data used in this study. The authors would like to thank the editor and the anonymous reviewers for their comments that helped to improve the quality of the paper.

Edited by: A. Guadagnini

Reviewed by: two anonymous referees

\section{References}

Abaza, M., Anctil, F., Fortin, V., and Turcotte, R.: Sequential streamflow assimilation for short-term hydrological ensemble forecasting, J. Hydrol., 519, 2692-2706, doi:10.1016/j.jhydrol.2014.08.038, 2014.

Allen, R. G., Pereira, L. S., Raes, D., and Smith, M.: Crop Evapotranspiration-Guidelines for Computing Crop Wa- ter Requirements-FAO Irrigation and Drainage Paper 56, Food and Agriculture Organization of the United Nations, Rome, Italy, 1998.

Andréassian, V., Parent, E., and Michel, C.: A distribution-free test to detect gradual changes in watershed behavior, Water Resour. Res., 39, 1252, doi:10.1029/2003WR002081, 2003.

Brigode, P., Oudin, L., and Perrin, C.: Hydrological model parameter instability: A source of additional uncertainty in estimating the hydrological impacts of climate change?, J. Hydrol., 476, 410-425, doi:10.1016/j.jhydrol.2012.11.012, 2013.

Brown, A. E., Zhang, L., McMahon, T. A., Western, A. W., and Vertessy, R. A.: A review of paired catchment studies for determining changes in water yield resulting from alterations in vegetation, J. Hydrol., 310, 28-61, doi:10.1016/j.jhydrol.2004.12.010, 2005.

Burgers, G., van Leeuwen, P. J., and Evensen, G.: Analysis scheme in the ensemble Kalman filter, Mon. Weather Rev., 126, 1719-1724, doi:10.1175/15200493(1998)126<1719:ASITEK>2.0.CO;2, 1998.

Clark, M. P., Rupp, D. E., Woods, R. A., Zheng, X., Ibbitt, R. P., Slater, A. G., Schmidt, J., and Uddstrom, M. J.: Hydrological data assimilation with the ensemble Kalman filter: Use of streamflow observations to update states in a distributed hydrological model, Adv. Water Resour., 31, 13091324, doi:10.1016/j.advwatres.2008.06.005, 2008.

Coron, L., Andréassian, V., Perrin, C., Lerat, J., Vaze, J., Bourqui, M., and Hendrickx, F.: Crash testing hydrological models in contrasted climate conditions: An experiment on 216 Australian catchments, Water Resour. Res., 48, W05552, doi:10.1029/2011WR011721, 2012.

DeChant, C. M. and Moradkhani, H.: Toward a reliable prediction of seasonal forecast uncertainty: Addressing model and initial condition uncertainty with ensemble data assimilation and sequential Bayesian combination, J. Hydrol., 519, 2967-2977, doi:10.1016/j.jhydrol.2014.05.045, 2014.

Delijani, E. B., Pishvaie, M. R., and Boozarjomehry, R. B.: Subsurface characterization with localized ensemble Kalman filter employing adaptive thresholding, Adv. Water Resour., 69, 181-196, doi:10.1016/j.advwatres.2014.04.011, 2014.

Deng, C., Liu, P., Guo, S., Wang, H., and Wang, D.: Estimation of nonfluctuating reservoir inflow from water level observations using methods based on flow continuity, J. Hydrol., 529, 11981210, doi:10.1016/j.jhydrol.2015.09.037, 2015a.

Deng, C., Liu, P., Liu, Y., Wu, Z. H., and Wang, D.: Integrated hydrologic and reservoir routing model for realtime water level forecasts, J. Hydrol. Eng., 20, 05014032, doi:10.1061/(ASCE)HE.1943-5584.0001138, 2015b.

Evensen, G.: Sequential data assimilation with a nonlinear quasi-geostrophic model using Monte Carlo methods to forecast error statistics, J. Geophys. Res., 99, 10143-10162, doi:10.1029/94JC00572, 1994.

Evensen, G.: The Ensemble Kalman filter: theoretical formulation and practical implementation, Ocean Dynam., 53, 343-367, doi:10.1007/s10236-003-0036-9, 2003.

Evensen, G. and van Leeuwen, P. J.: Assimilation of Geosat altimeter data for the Agulhas Current using the ensemble Kalman filter with a quasigeostrophic model, Mon. Weather Rev., 124, 85-96, doi:10.1175/1520-0493(1996)124<0085:AOGADF>2.0.CO;2, 1996. 
Guo, S., Wang, J., Xiong, L., Ying, A., and Li, D.: A macroscale and semi-distributed monthly water balance model to predict climate change impacts in China, J. Hydrol., 268, 1-15, doi:10.1016/S0022-1694(02)00075-6, 2002.

Guo, S., Chen, H., Zhang, H., Xiong, L., Liu, P., Pang, B., Wang, G., and Wang, Y.: A semi-distributed monthly water balance model and its application in a climate change impact study in the middle and lower Yellow River basin, Water Int., 30, 250-260, doi:10.1080/02508060508691864, 2005.

Han, E., Merwade, V., and Heathman, G. C.: Implementation of surface soil moisture data assimilation with watershed scale distributed hydrological model, J. Hydrol., 416-417, 98-117, doi:10.1016/j.jhydrol.2011.11.039, 2012.

Jeremiah, E., Marshall, L., Sisson, S. A., and Sharma, A.: Specifying a hierarchical mixture of experts for hydrologic modeling: Gating function variable selection, Water Resour. Res., 49, 29262939, doi:10.1002/wrcr.20150, 2013.

Kumar, S. V., Reichle, R. H., Harrison, K. W., Peters-Lidard, C. D., Yatheendradas, S., and Santanello, J. A.: A comparison of methods for a priori bias correction in soil moisture data assimilation, Water Resour. Res., 48, W03515, doi:10.1029/2010WR010261, 2012.

Kurtz, W., Hendricks Franssen, H.-J., and Vereecken, H.: Identification of time-variant river bed properties with the ensemble Kalman filter, Water Resour. Res., 48, W10534, doi:10.1029/2011WR011743, 2012.

Li, S., Xiong, L., Dong, L., and Zhang, J.: Effects of the Three Gorges Reservoir on the hydrological droughts at the downstream Yichang station during 2003-2011, Hydrol. Process., 27, 3981-3993, doi:10.1002/hyp.9541, 2013.

Li, X.-N., Xie, P., Li, B.-B., and Zhang, B.: A probability calculation method for different grade drought event under changing environment-Taking Wuding River basin as an example, Shuili Xuebao, J. Hydraul. Eng., 45, 585-594, doi:10.13243/j.cnki.slxb.2014.05.010, 2014 (in Chinese).

Li, Y., Ryu, D., Western, A. W., and Wang, Q. J.: Assimilation of stream discharge for flood forecasting: The benefits of accounting for routing time lags, Water Resour. Res., 49, 1887-1900, doi:10.1002/wrcr.20169, 2013.

Li, Z., Liu, P., Deng, C., Guo, S., He, P., and Wang, C.: Evaluation of the estimation of distribution algorithm to calibrate a computationally intensive hydrologic model, J. Hydrol. Eng., 21, 04016012, doi:10.1061/(ASCE)HE.1943-5584.0001350, 2015.

Liu, Y. and Gupta, H. V.: Uncertainty in hydrologic modeling: Toward an integrated data assimilation framework, Water Resour. Res., 43, 1-18, doi:10.1029/2006WR005756, 2007.

Liu, Y., Weerts, A. H., Clark, M., Hendricks Franssen, H.-J., Kumar, S., Moradkhani, H., Seo, D.-J., Schwanenberg, D., Smith, P., van Dijk, A. I. J. M., van Velzen, N., He, M., Lee, H., Noh, S. J., Rakovec, O., and Restrepo, P.: Advancing data assimilation in operational hydrologic forecasting: progresses, challenges, and emerging opportunities, Hydrol. Earth Syst. Sci., 16, 3863-3887, doi:10.5194/hess-16-3863-2012, 2012.

Lü, H. S., Hou, T., Horton, R., Zhu, Y. H., Chen, X., Jia, Y. W., Wang, W., and Fu, X. L.: The streamflow estimation using the Xinanjiang rainfall runoff model and dual state-parameter estimation method, J. Hydrol., 480, 102-114, doi:10.1016/j.jhydrol.2012.12.011, 2013.
Merz, R., Parajka, J., and Blöschl, G.: Time stability of catchment model parameters: Implications for climate impact analyses, Water Resour. Res., 47, W02531, doi:10.1029/2010WR009505, 2011.

Montzka, C., Grant, J. P., Moradkhani, H., Franssen, H.-J. H., Weihermüller, L., Drusch, M., and Vereecken, H.: Estimation of radiative transfer parameters from L-band passive microwave brightness temperatures using advanced data assimilation, Vadose Zone J., 12, 1-17, doi:10.2136/vzj2012.0040, 2013.

Moradkhani, H., Sorooshian, S., Gupta, H. V., and Houser, P. R.: Dual state-parameter estimation of hydrological models using ensemble Kalman filter, Adv. Water Resour., 28, 135-147, doi:10.1016/j.advwatres.2004.09.002, 2005.

Nash, J. E. and Sutcliffe, J. V.: River flow forecasting through conceptual models part I: A discussion of principles, J. Hydrol., 10, 282-290, doi:10.1016/0022-1694(70)90255-6, 1970.

Nie, S., Zhu, J., and Luo, Y.: Simultaneous estimation of land surface scheme states and parameters using the ensemble Kalman filter: identical twin experiments, Hydrol. Earth Syst. Sci., 15, 2437-2457, doi:10.5194/hess-15-2437-2011, 2011.

Paik, K., Kim, J. H., Kim, H. S., and Lee, D. R.: A conceptual rainfall-runoff model considering seasonal variation, Hydrol. Process., 19, 3837-3850, doi:10.1002/hyp.5984, 2005.

Panzeri, M., Riva, M., Guadagnini, A., and Neuman, S. P.: Data assimilation and parameter estimation via ensemble Kalman filter coupled with stochastic moment equations of transient groundwater flow, Water Resour. Res., 49, 1334-1344, doi:10.1002/wrcr.20113, 2013.

Patil, S. D. and Stieglitz, M.: Comparing spatial and temporal transferability of hydrological model parameters, J. Hydrol., 525, 409-417, doi:10.1016/j.jhydrol.2015.04.003, 2015.

Pauwels, V. R. N. and Lannoy, G. J. M. D.: Improvement of Modeled Soil Wetness Conditions and Turbulent Fluxes through the Assimilation of Observed Discharge, J. Hydrometeorol., 7, 458477, doi:10.1175/JHM490.1, 2006.

Peel, M. C. and Blöschl, G.: Hydrological modelling in a changing world, Prog. Phys. Geog., 35, 249-261, doi:10.1177/0309133311402550, 2011.

Samuel, J., Coulibaly, P., Dumedah, G., and Moradkhani, H.: Assessing model state and forecasts variation in hydrologic data assimilation, J. Hydrol., 513, 127-141, doi:10.1016/j.jhydrol.2014.03.048, 2014.

Seiller, G., Anctil, F., and Perrin, C.: Multimodel evaluation of twenty lumped hydrological models under contrasted climate conditions, Hydrol. Earth Syst. Sci., 16, 1171-1189, doi:10.5194/hess-16-1171-2012, 2012.

Shi, Y., Davis, K. J., Zhang, F., Duffy, C. J., and Yu, X.: Parameter estimation of a physically based land surface hydrologic model using the ensemble Kalman filter: A synthetic experiment, Water Resour. Res., 50, 706-724, doi:10.1002/2013WR014070, 2014.

$\mathrm{Su}, \mathrm{T}$., Feng, T., and Feng, G.: Evaporation variability under climate warming in five reanalyses and its association with pan evaporation over China, J. Geophys. Res.-Atmos., 120, 8080-8098, doi:10.1002/2014JD023040, 2015.

Tamura, H., Bacopoulos, P., Wang, D., Hagen, S. C., and Kubatko, E. J.: State estimation of tidal hydrodynamics using ensemble Kalman filter, Adv. Water Resour., 63, 45-56, doi:10.1016/j.advwatres.2013.11.002, 2014. 
Thirel, G., Andréassian, V., Perrin, C., Audouy, J. N., Berthet, L., Edwards, P., Folton, N., Furusho, C., Kuentz, A., Lerat, J., Lindström, G., Martin, E., Mathevet, T., Merz, R., Parajka, J., Ruelland, D., and Vaze, J.: Hydrology under change: an evaluation protocol to investigate how hydrological models deal with changing catchments, Hydrolog. Sci. J., 60, 1184-1199, doi:10.1080/02626667.2014.967248, 2015.

Vrugt, J. A., ter Braak, C. J. F., Diks, C. G. H., and Schoups, G.: Hydrologic data assimilation using particle Markov chain Monte Carlo simulation: Theory, concepts and applications, Adv. Water Resour., 51, 457-478, doi:10.1016/j.advwatres.2012.04.002, 2013.

Wang, D., Chen, Y., and Cai, X.: State and parameter estimation of hydrologic models using the constrained ensemble Kalman filter, Water Resour. Res., 45, W11416, doi:10.1029/2008WR007401, 2009.

Wang, G. and Fan, Z.: A study of water and sediment changes in the Yellow River, Publishing House of Yellow River Water Conservancy, Zhengzhou, China, 2003 (in Chinese).

Weerts, A. H. and El Serafy, G. Y. H.: Particle filtering and ensemble Kalman filtering for state updating with hydrological conceptual rainfall-runoff models, Water Resour. Res., 42, 1-17, doi:10.1029/2005WR004093, 2006.

Westra, S., Thyer, M., Leonard, M., Kavetski, D., and Lambert, M.: A strategy for diagnosing and interpreting hydrological model nonstationarity, Water Resour. Res., 50, 5090-5113, doi:10.1002/2013WR014719, 2014.

Xie, X. and Zhang, D.: Data assimilation for distributed hydrological catchment modeling via ensemble Kalman filter, Adv. Water Resour., 33, 678-690, doi:10.1016/j.advwatres.2010.03.012, 2010.

Xie, X. and Zhang, D.: A partitioned update scheme for stateparameter estimation of distributed hydrologic models based on the ensemble Kalman filter, Water Resour. Res., 49, 7350-7365, doi:10.1002/2012WR012853, 2013.

Xie, X., Meng, S., Liang, S., and Yao, Y.: Improving streamflow predictions at ungauged locations with real-time updating: application of an EnKF-based state-parameter estimation strategy, Hydrol. Earth Syst. Sci., 18, 3923-3936, doi:10.5194/hess-183923-2014, 2014.
Xiong, L. and Guo, S.: A two-parameter monthly water balance model and its application, J. Hydrol., 216, 111-123, doi:10.1016/S0022-1694(98)00297-2, 1999.

Xiong, L. and Guo, S.: Appraisal of Budyko formula in calculating long-term water balance in humid watersheds of southern China, Hydrol. Process., 26, 1370-1378, doi:10.1002/hyp.8273, 2012.

Xiong, L., Yu, K.-X., and Gottschalk, L.: Estimation of the distribution of annual runoff from climatic variables using copulas, Water Resour. Res., 50, 7134-7152, doi:10.1002/2013WR015159, 2014.

$\mathrm{Xu}, \mathrm{J} .:$ Variation in annual runoff of the Wudinghe River as influenced by climate change and human activity, Quatern. Int., 244 230-237, doi:10.1016/j.quaint.2010.09.014, 2011.

Xue, L. and Zhang, D.: A multimodel data assimilation framework via the ensemble Kalman filter, Water Resour. Res., 50, 41974219, doi:10.1002/2013WR014525, 2014.

Yan, H., DeChant, C. M., and Moradkhani, H.: Improving soil moisture profile prediction with the particle filter-Markov chain Monte Marlo method, IEEE T. Geosci. Remote, 53, 6134-6147, doi:10.1109/tgrs.2015.2432067, 2015.

Ye, W., Bates, B. C., Viney, N. R., Sivapalan, M., and Jakeman, A. J.: Performance of conceptual rainfall-runoff models in lowyielding ephemeral catchments, Water Resour. Res., 33, 153166, doi:10.1029/96WR02840, 1997.

Zhang, D., Liu, X. M., Liu, C. M., and Bai, P.: Responses of runoff to climatic variation and human activities in the Fenhe River, China, Stoch. Env. Res. Risk A., 27, 1293-1301, doi:10.1007/s00477-012-0665-y, 2013.

Zhang, H., Huang, G. H., Wang, D., and Zhang, X.: Multi-period calibration of a semi-distributed hydrological model based on hydroclimatic clustering, Adv. Water Resour., 34, 1292-1303, doi:10.1016/j.advwatres.2011.06.005, 2011. 